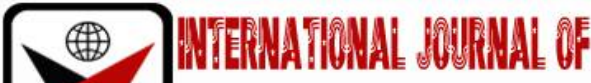

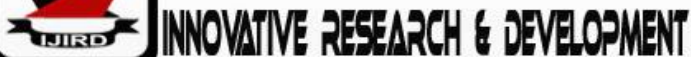

ISSN 2278-0211 (Online)

\section{Ontology of Vernacular Interior and Exterior House Decorations in East Africa}

\author{
Omindi Sonia \\ Master's Student, Department of Art and Design, University of Nairobi, Kenya \\ Dr. Maina Mwituria \\ Lecturer, Department of Art and Design, University of Nairobi, Kenya
}

\begin{abstract}
:
Vernacular architecture evolves over time reflecting the characteristics of the local environment, climate, culture, natural materials, technology and the experience of centuries of community building. Mostly, men build the house and the women decorate the facades. All the figures have a symbolic meaning. This paper studied east African vernacular wall decorations from an art and design point of view. The objective was to document the fast fading cultural practices for posterity and for academics. Conducted in Nairobi, the domain of interest was east African cultures. The study used desktop and field research methods. It formed part of the annual research output seminars and symposia of the school of the arts and design of the University Of Nairobi, Kenya. The papers studied the following museums, heritages and contemporary spaces: King's Palace Museum in Rwanda, the Nubian House, the Rabe family house, various huts decoration and design in Uganda, The church martyrs' museum in Uganda and the Oasis Diani Villa in Kenya.

From the study, it emerged that East African vernacular building styles are culturally rich, and decorating the walls of their buildings is an important part of their cultural legacy. Wall decorating is always a community project done by the women and it's a very ancient practice that dates from the sixteenth century AD.' The study concluded that Interior and exterior decorations in East Africa is one of the African heritage being practiced up to now. This is mainly done by women who pass their skill to their daughters from generation to generation. Although most of them are not being practiced today, there are those that have been turned to museum while others have contemporary influence.
\end{abstract}

Keywords: Museum, Heritage, Huts, Villa, Exterior and interior decoration

\section{Introduction}

Numerous varieties of shapes, full of colors have enriched Africa. These things with visually attractive power have arranged Africa. Pattern making is an instinctive thing. The throbbing of maize in a bowl provides the same feeling as the trampling of tincture on fabric. The interlacing of hair braids is the same soft rhythmic exercise as plucking at an mbira (Evans, 2010).

Throughout everywhere, patterns can be visualized and conceptualized. Insight of patterning can be obtained from every elements of a plant like leaves, pods, seeds etc. Innovative patterns got generated in the shadow of trees during the afternoon. It creates a hiding shield on animals, birds and insects (Evans, 2010).

In East Africa, house decorations were mainly done by women and girls and passed from generation to generation as illustrated in figure 1 below. They mainly used what was available at a particular time and place. But due to influence of the modern design, there is the introduction of new materials like paint and brushes. They draw their inspiration from nature and use vibrant colors to come up with the designs. Although the traditional decoration is being lost, some have been preserved as museum while others have an additional contemporary touch. But one can still get the feel of the vernacular decorations. Few of the decorations have been documented since they are not long lasting. For the purpose of this study, selected case studies were analyzed from preserved wall decorations around East Africa. 


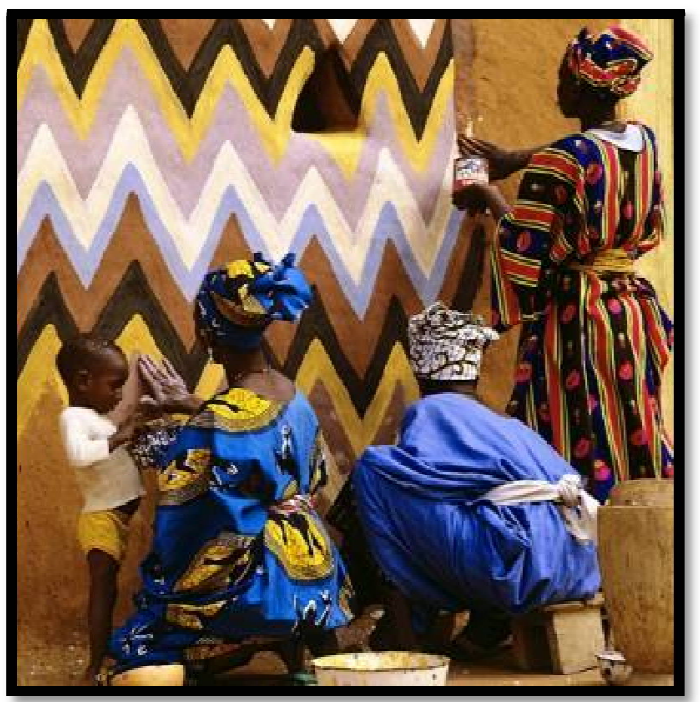

Figure 1: Women Painting Decorations on Exterior Walls Source: Contemporarypatterns.Com/15.12.2019

\section{Theory}

\subsection{The Interior Decoration of the King's Palace in Nyanza, Rwanda}

There is little history documented on the vernacular interior and exterior decorations of the palace. What is really noted down was the significance of the layouts. As designers, we tend to be curious of how the decorations were done and the type of materials that were being used. The king's palace has been termed as a historical heritage in Rwanda where tourists get to learn about the building. It has vernacular type of interior and exterior decoration. Although some of the interior artefacts were stolen during the genocide, those that were left have been preserved and also the renovations over the period of time help in preserving the history. Until 1959, Rwanda's King lived in the Palace. All huts had a spike at the center of the roof. Only the King's Palace had three spikes on top. The lower two spikes represent the horns of the King's traditional cattle. Whenever the King died, the next King (son or brother of the last king) was required to construct a new palace (Kings Palace, n.d.). Every hut has only one entrance. The entrance to the King's Palace has unique features. The King's stool is just inside the entrance on the left. Visitors were required to remove their shoes and enter over the white ridge on the floor after they received permission from the King. The Main Chamber of the King's Palace, fireplace, as illustrated in figure 1, is just out of view in the foreground. Figure 2 shows the woven floor mats with layers of grass underneath which makes for soft, muffled walking.

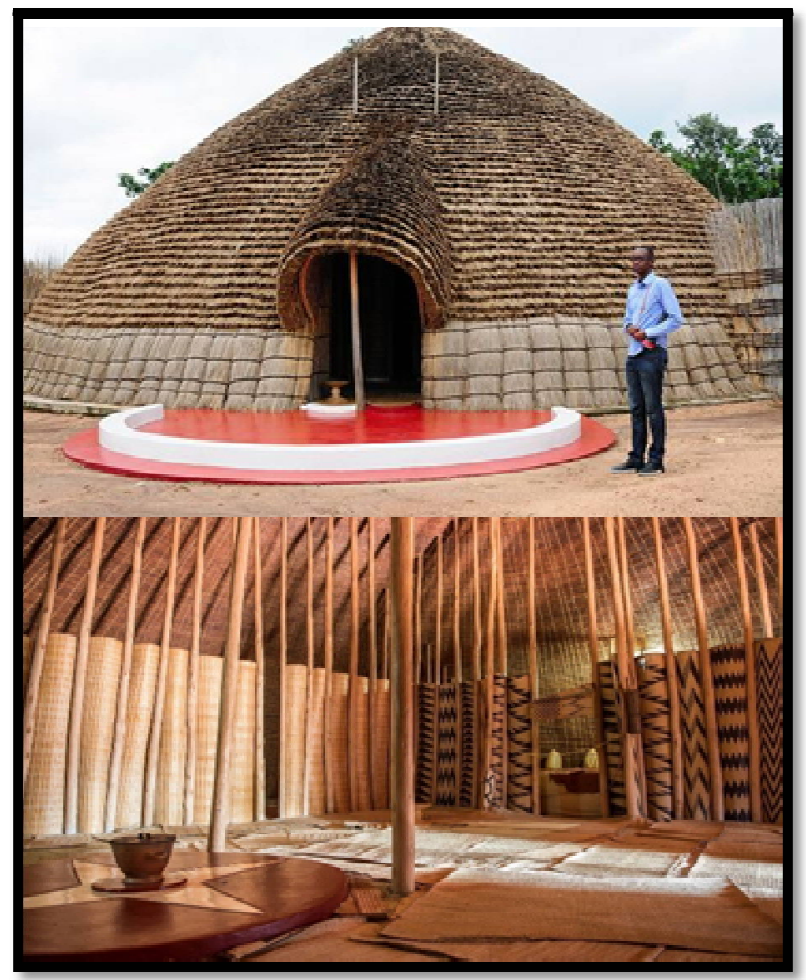

Figure 2: Woven Floormats in the King's Palace Source: King's Palace Museum/Rwandaguide.Info 
The vertical semicircular room dividers of woven plant fibers as seen (Fig 2) separate the main room from the King's bedroom which is entered via the central opening. From the Main Chamber looking to the Entrance of the Palace the interior is softly lit as outdoor light filters through the bamboo screens.

The exterior of thatch made of elephant grass and interior of woven bamboo in figure 3 provide excellent waterproofing and insulation. Even when the tropical sun is fiercely hot, the inside temperature remains very comfortable the interior is simple: A couple of traditionally woven mats cover the floor on which lay traditional gourds, utensils and baskets(Kings Palace, n.d.)

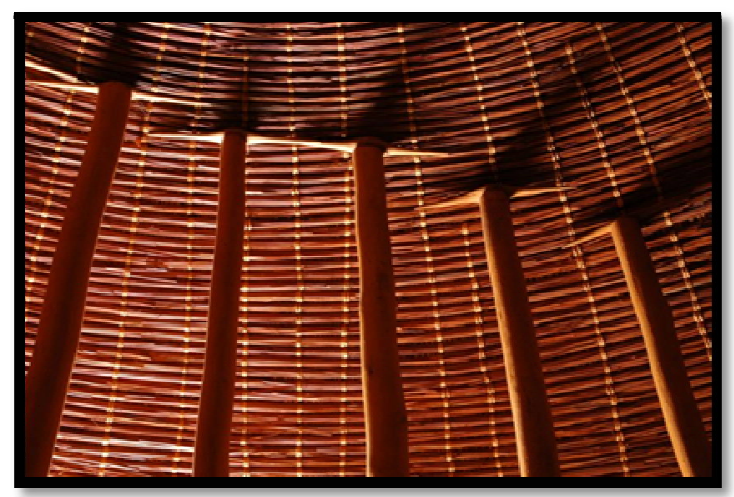

Figure 3: Spikes to Support the Ceiling Source: King's Palace Museum/Rwandaguide.Info

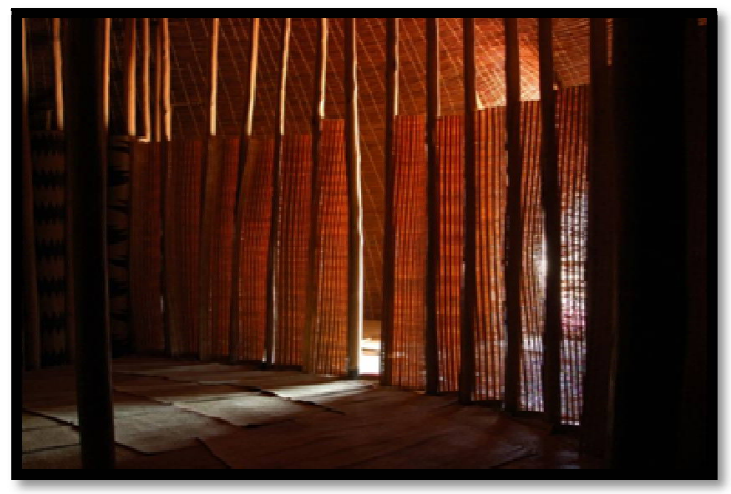

Figure 4: Bamboo Screen

Source: King's Palace Museum/Rwandaguide.Info

\subsection{The Decorated Houses of Nubia}

Ornamentation mainly deals with the home's exterior doorway. Doorway is a connecting wing to inner patio or lead directly into a greeting room. The Nubian house is being generally built with mud with the joint effort of men and women. The decoration of doorway is done with dried crocodile heads, painted fish (Figure 5). Some courtyard are generally decorated with the wings of a dried pelican echo the arches behind it (fig 6) (Louis Wemer, 2006).

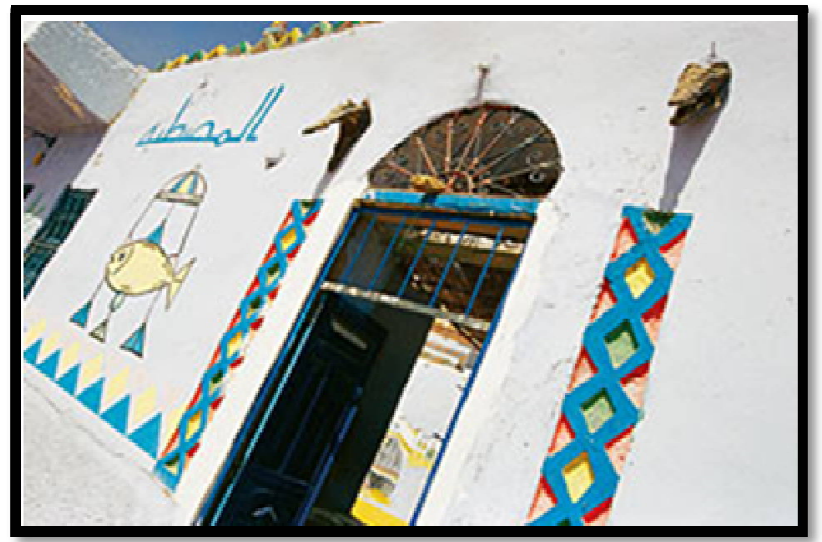

Figure 5: Dried Crocodile Heads, One Dried and One Painted Fish and Geometric Plaster Carving Decorates The Hallway And Wall Of A Home. Source: Archives.Aramcoworld.Com/Accessed On 15.12.2019 


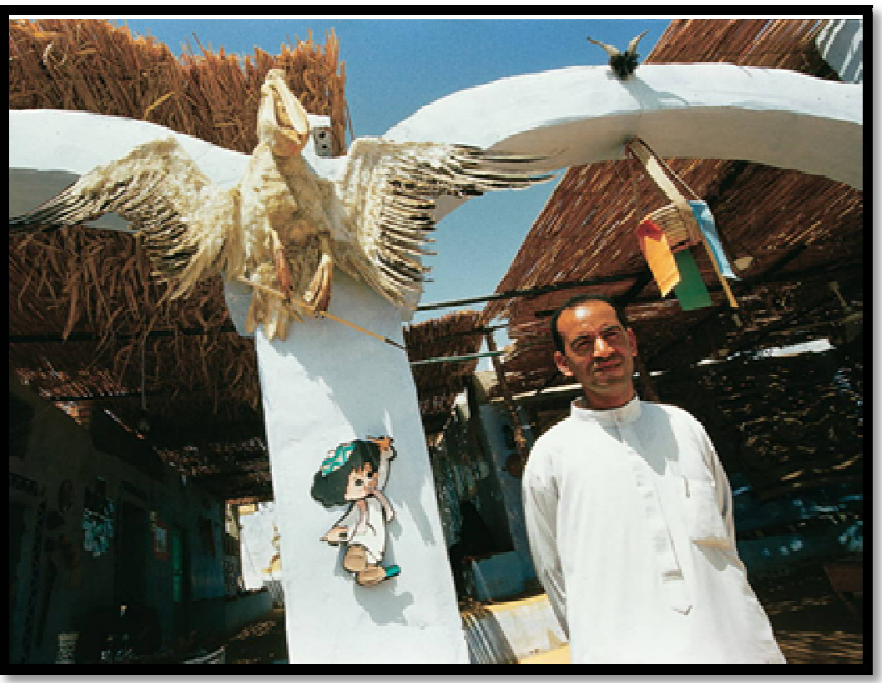

Figure 6: The Wings of a Dried Pelican Echo the Arches

Source: Archives.Aramcoworld.Com/ Accessed On 15.12.2019

Compared to layout of floors, exterior doorways are being done with distinctive shapes, colorful decorators. Various types of decorative items like mirrors, cow horns ceramic plates, automobile headlights, and dried crocodiles are often used. Along the course of time, materials have been changed for decoration. But, still now doorway reflects the status and taste of family. It is also a way to attract and welcome the guests (Louis Wemer, 2006).

A man born on Badeen Island in mid-channel, lived in such a house near Kerma. His name was Abdallah Salih Suleiman. This person talked about the decorations of his house made by a lion holding a sword, surrounded by sunbursts. They also had another decoration which they called sadeeq al-mazreeq, or friend of the fields. This decoration helps to welcome visitors. Figure 8 illustrates painted motifs, plaster carving and, in the blind arch above the door, a crocodile head decorating the home.

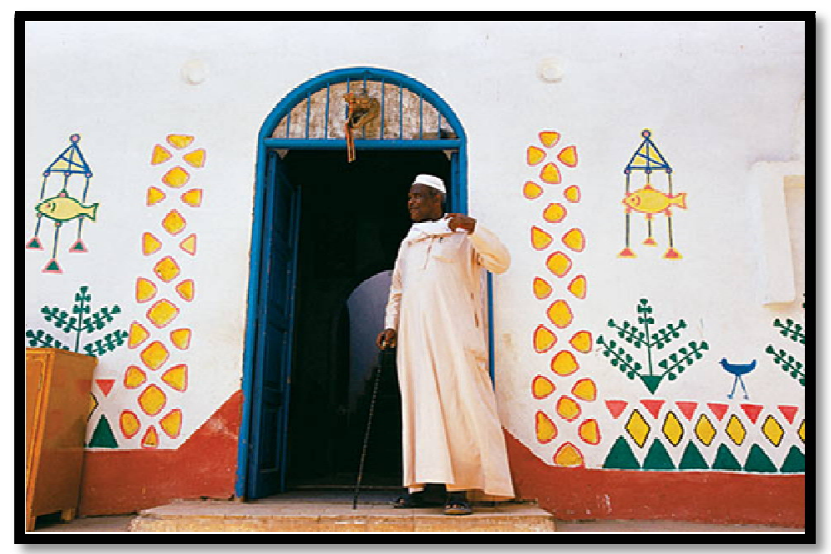

Figure 7: Painted Motifs, Plaster Carvings and Crocodile Head in the Blind Arch above the Door

Source: Archives.Aramcoworld.Com/ Accessed On 15/11/2019

Generally, at the initial stage huts are being prepared for two people. This gets extended when newly married couples take up residence and require their own private room (Louis Wemer, 2006). Marian Wenzel, in her book 'House Decoration in Nubia' (University of Toronto Press, 1972), highlighted the methods of art criticism to social anthropology. She determined that the iconography of Nubian house décor was a 20th-century phenomenon, traceable to the handiwork of a few known builders-turned-artists (Louis Wemer, 2006).

After iron railroad rail got available, the demand for creating decorated wall got increased. The builder-artist, Ahmad Batoul did many contributions for the Nubian style (Louis Wemer, 2006). Batoul worked in domain related to decoration of the exterior walls. Ceramic plates and saucers are one of the most popular materials used for decorations. Yellow and red stone-based pigments were being mostly used in the rocky parts of northern Mahas. The introduction of brighter artificial pigments, fade away the usage of the monochromatic colors (Louis Wemer, 2006).

\subsection{The Rabe Family Home}

Figure 8 represents the traditional houses decorated in bright colours. The Nubian basketry decorates the walls. From ancient timing fish were often used in the tomb scenes. Figure 9 depicted the plants associated with river Nile often appeared on Kemite temples as offerings. It also gave a reference to the annual inundation (flood) and the fertility of the Black Land (Ashton, n.d.). 


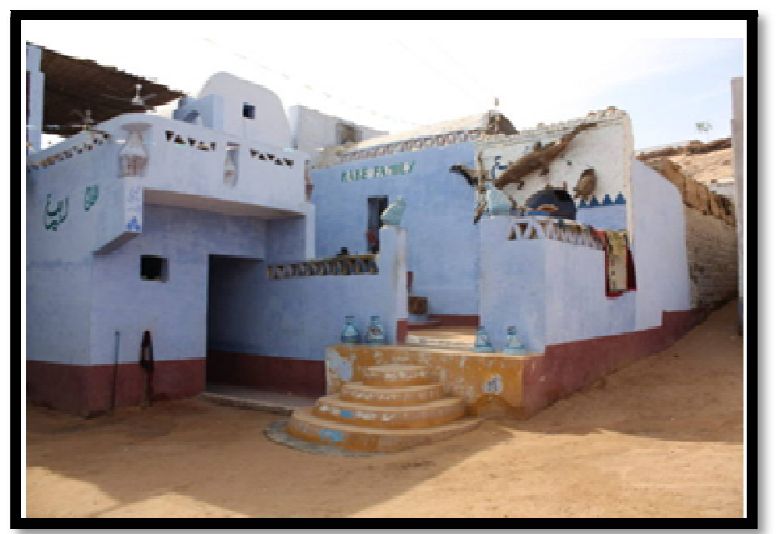

Figure 8: Brightly Colored Walls of the Rabe Family Home Source: Kemetexpert.Com/ Accessed On 15.11.2019

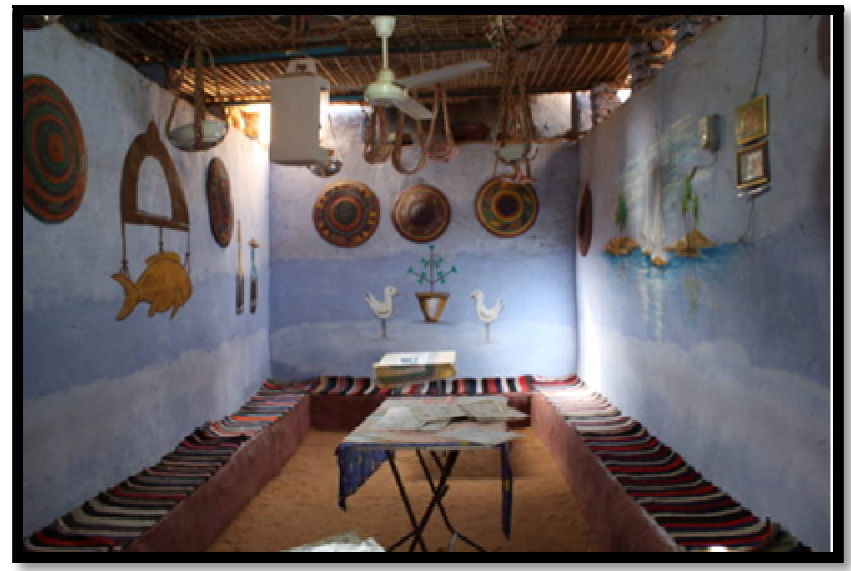

Figure 9: Inside Decoration of the Rabe Family Home Source: Kemetexpert.Com/ Accessed On 15.11.2019

Traditional Nubian homes decorated with crocodiles as shown in the figure. This was done to reflect the tradition. When Herodotus, the Greek historian, visited Kemet he talked about being confused that the Egyptians (Ashton, n.d.).

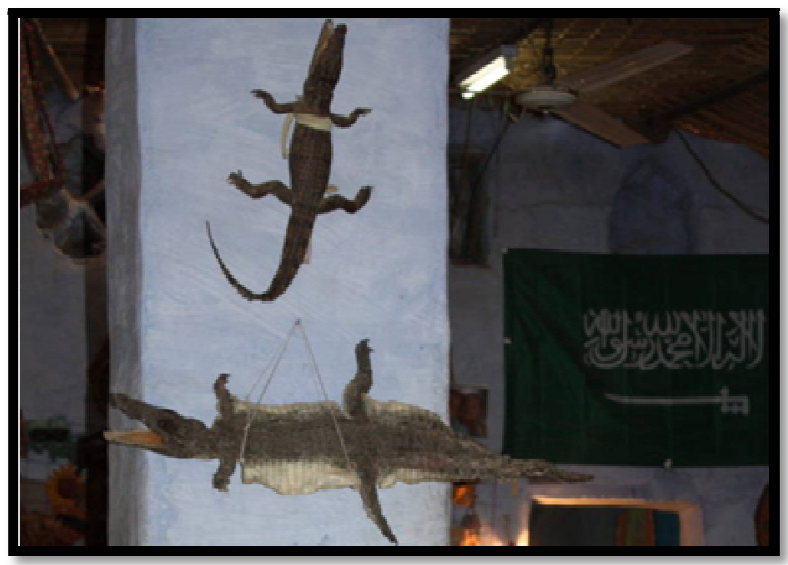

Figure 10: Crocodile Used for Decoration of the Rabe Family Home Source: Kemetexpert.Com/Accessed on 15.11.2019

Figure 11 highlighted the outside decoration of a traditional Nubian house. Basketry is also a traditional craft in Africa. Baskets are used to cover food, serve food and also store food. The Nubian Heritage Village is so relevant that it helps preserve the past, present and future (Ashton, n.d.). 


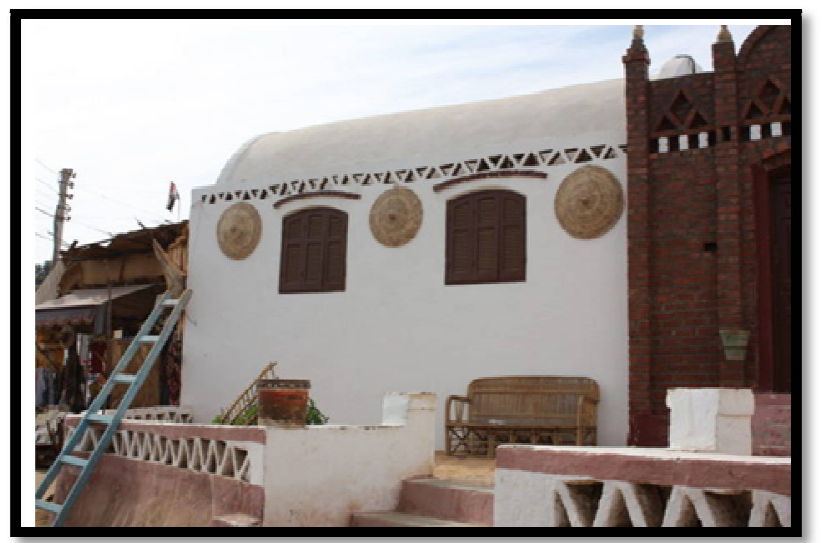

Figure 11; Baskets Decorate the Outside of a Nubian House Source: Kemetexpert.Com/ Accessed On 15.11.2019

\subsection{Uganda's Decorations}

The huts are small in size and consist of single person or utmost two. According to Dr Stephen Mukiibi, chair of Architecture School of the Built Environment at the College of Engineering, Design, Art and Technology, Makerere University, huts are used for protection. At night they slept in the hut to protect themselves. Vernacular Architecture, which was used by many people in the western region, series edited by Dr Barnabas Nawangwe at the beginning of the 21st century.

\subsection{Types of Huts, According to Ethnicities in Ugandahima Hut}

Hut is generally prepared with a straw dome, which woven in a spiral pattern to create a basketlike skeleton. Woven sticks are used popularly to separate the bedroom from rest of the hut. Orugyegye is kind of platform to keep milk pots. A small platform that connects the door way to bedrooms often has skin spread on it. Wives can sit on it to receive the milk (Omurungi, 2012).

\subsubsection{Nkore Hut}

Wooden poles are used to prepare this hut. Spear grasses are used for the roof. Two reed pillars support the roof to the veranda. The roof is of conical shape. Coloring done with the plain earth colours (Omurungi, 2012)

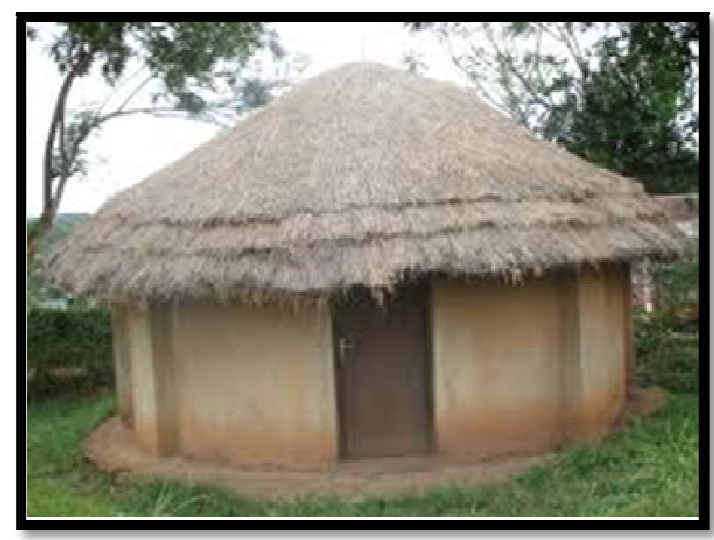

Figure12: Nkore Hut Design

Source: Google Photos: Nkore Hut/Accessed on 15.11.2019

\subsubsection{Madi Hut}

Here, partitions between walls are being created by the rectangular columns. They are distanced equally (Omurungi, 2012). 


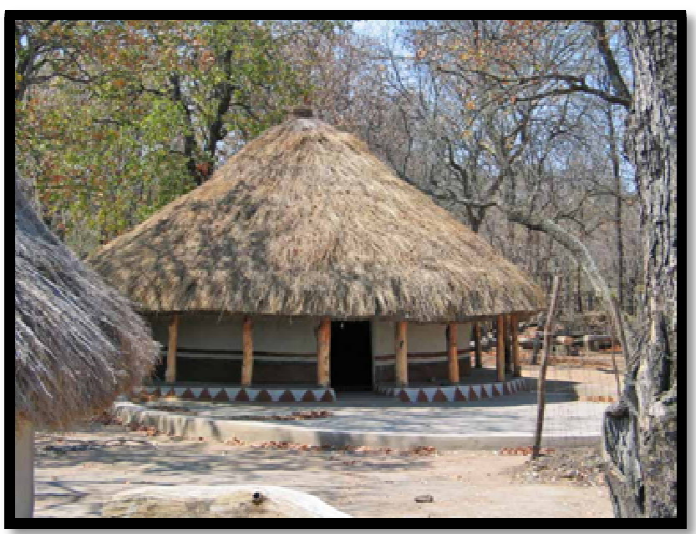

Figure 13: Madi Hut

\subsubsection{Karamojong Hut}

In the centre of this hut, a dugout fireplace was being prepared where a permanent fire burns - sometimes for a lifetime. A small passage is present at the entrance. To protect the hut from wind poles put around the hut. Roof is made with grass. (Omurungi, 2012).

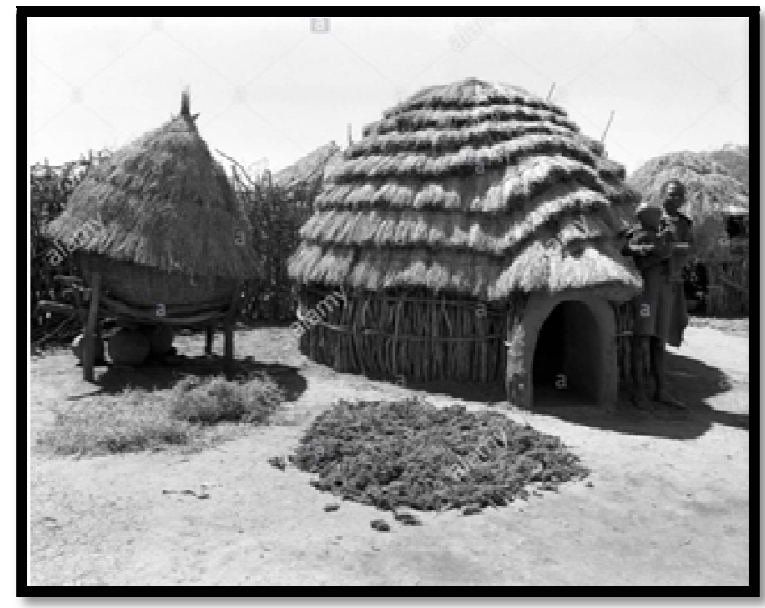

Figure 14: Karamojong Hut

Source: https://www.alamy.com/accessed on 4/4/2020

\subsubsection{Iteso Hut}

Both mud and a wooden framework used for the wall preparation. One central pole supports the roof. The roof is mainly grass-thatched. Plain earth colors are being used to paint the walls. Black soil, sometimes mixed with cow dung used for the floor preparation (Omurungi, 2012).

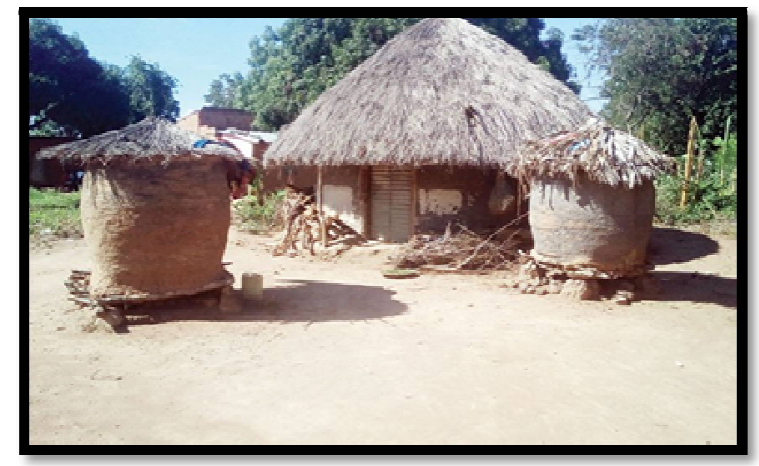

Figure 15: Iteso Hut

Source: $h$ ttps:// accessed on allafrica.com/4/4/2020

\subsubsection{Ganda Hut}

Frame work poles are used to prepare the conical roofing for this type of hut. Thick grass used for the floor. Interior ceiling prepared with concentric rings. Verandah prepared with woven reed work and partitions are made by backcloth (Omurungi, 2012). 


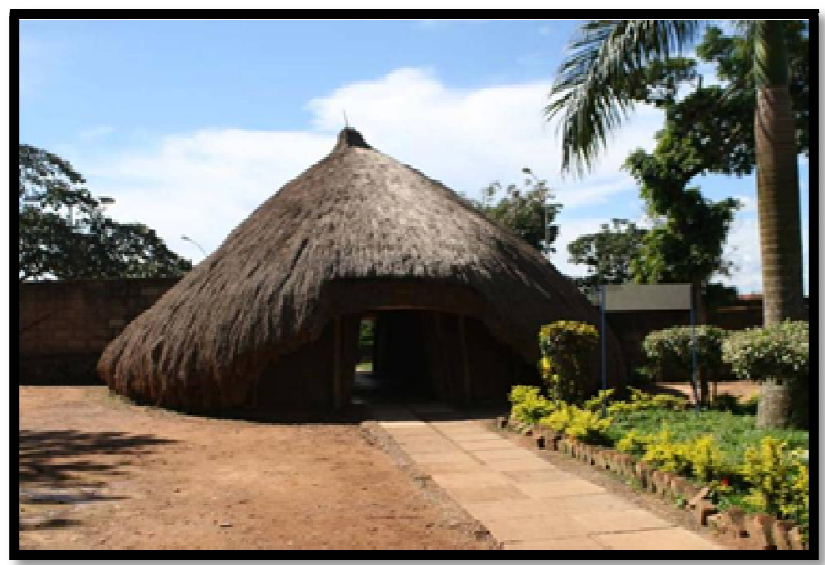

Figure 16: Ganda Hut

Source: https://www.southworld.net/accessed on 4/4/2020

\subsubsection{Soga Hut}

Mud is the most important component in the preparation of this type of hut. Wattle walls tied with strong poles. Bundles of spear grass are being tied together to build the roof. Anthill soils and cow dung are used for preparation of the walls and ground floor. The living and bedding room's partition is being made by the reed work. Natural earth pigment paints used to make the outside wall surfaces more attractive (Omurungi, 2012).

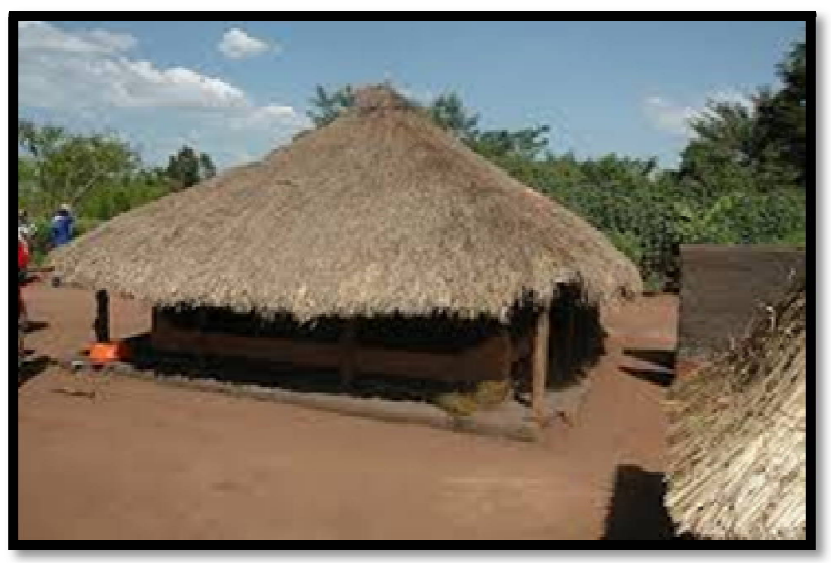

Figure 17: Busoga Hut

Source: https://www.flickr.com/ accessed on 4/4/2020

\subsection{The Church of Matyrs- Museum}

There is the museum of the church of martyrs that mainly focusses on the Christianity but its original design was adapted from the vernacular architecture. It is round in shape and its exterior has a painting although it seems recent but it is a form of decoration as illustrated in the figure below(Admin, 2019).

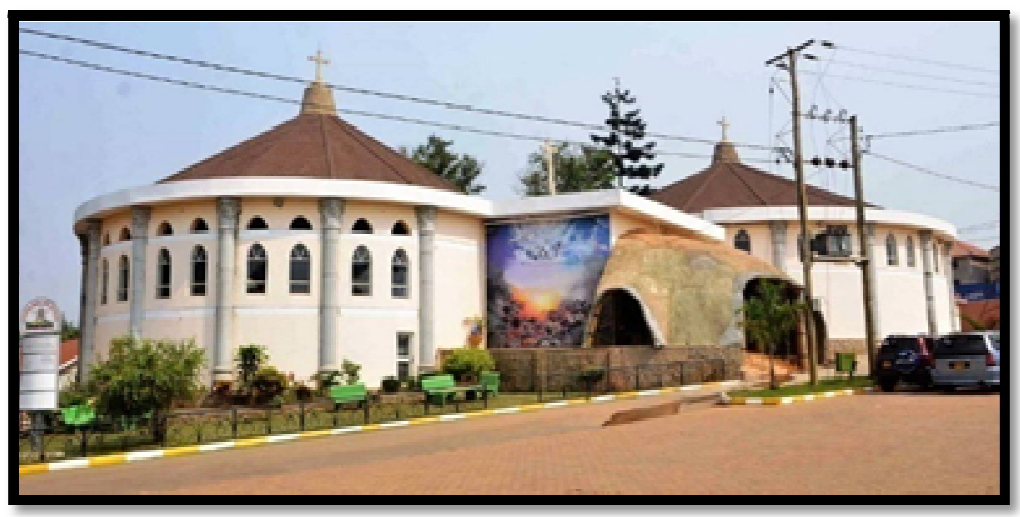

Figure 18: Church of Uganda Martyrs

Source: Google photos: church of Uganda museum/ accessed on 15.11.2019

\subsection{Oasis Diani Villas-Mombasa, Kenya}

The villas are decorated in such a way that they incorporate the African traditional decorations. There are 4 types of villas namely: the yellow villa, red villa, purple villa and the green villa. As the name suggests they have an exterior 
decoration of the named color. As for the pillars outside the villas, they are made out of wood and have some carvings on them that are painted white. In the interiors, the walls have an impression of hand-painted African safari themes. The figures below illustrate the various spaces.

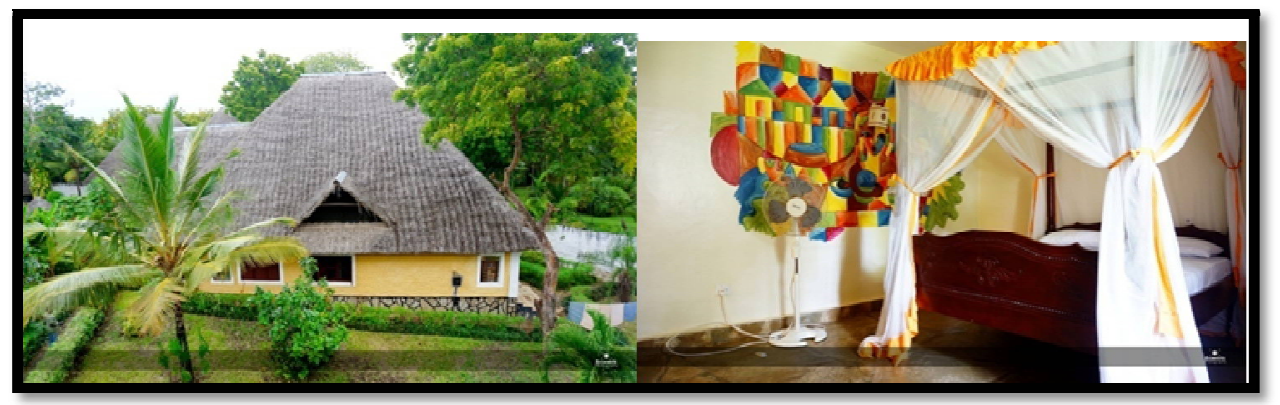

Figure 19: Yellow Villa and Its Interior Source: Googlephotos/Oasisvilla/15.11.2019

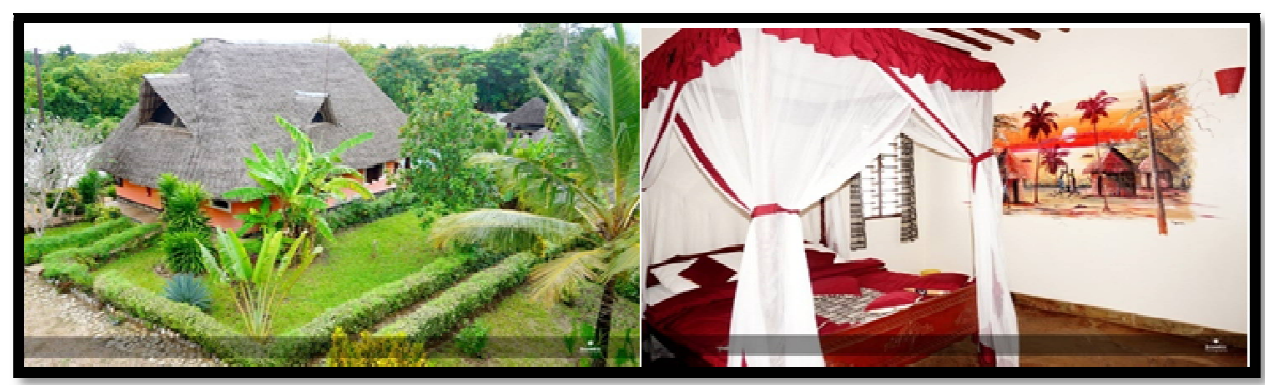

Figure 20: Red Villa and Its Interior

Source: Google Photos/Oasisvilla/Accessed on 15.11.2019

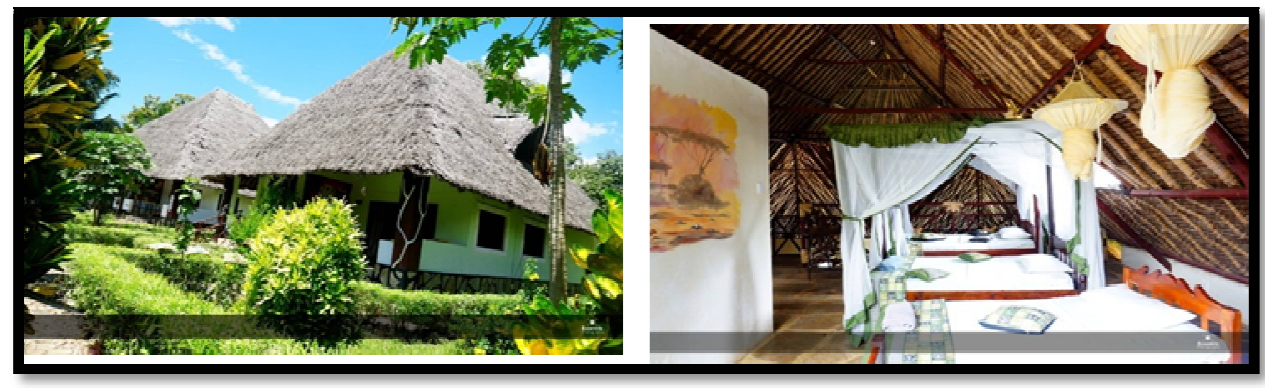

Figure 21: Green Villa and Its Interior

Source: Googlephotos/oasisvilla/ accessed on 15.11.2019

\section{Methods of Collecting Data}

Desktop research was the main method used. It was followed studies where artifacts were available. Key informants were also interviewed on diverse topics depending on field of expertise. Photography was also conducted to supplement the other two. Resultant data was analysed through thematic methods. Final results were presented through PowerPoint presentations in seminars and annual symposia. Finally, the journal output was forwarded to academic journal for publication.

\section{Findings}

From the study, it emerged that African tradition is slowly fading away as it continues to get infused with foreign cultures. It also emerged that little of vernacular wall decoration of east Africa has been documented as art. Concerted efforts are however evident of governments and institutions trying to preserve vernacular architecture for tourism a posterity just as was the goal of this study.

\section{Conclusion}

There is a lot of information about vernacular architecture of other African countries but when it comes to East Africa, it is challenging to get the information one requires. It is therefore imperative on academia and other stake holders to preserve east African heritage so that with time it can form a body of knowledge to educate future generations. Designers should also look to the older generations on how they came up with the design so as to improve or implement in contemporarily. 


\section{References}

i. Ashton, D. S. (n.d.). kemet Expert. Retrieved from African centred Egyptology: https://kemertexpert.com/aboutthis-blog/

ii. Evans, B. (2010). An ode to my proffession. Retrieved from http://www.contemporary-africanart.com/contemporary.

iii. Kings Palace. (n.d.). Retrieved from Visit Rwanda: https:// www.visitrwanda.com/interests/kings-palace/

iv. Louis Wemer, M. N. (2006). Decorated Houses of Nubia. Retrieved from aramcoworld: https://archive.aramcoworld.com

v. Admin. (2019). Uganda Tourism. Church of Uganda matyrs' Museum.

vi. Omurungi, S. (2012). Daily Monitor. The Hut; The first Building in Uganda. 